\title{
EVALUATION OF LOCAL DAMAGE TO REINFORCED CONCRETE PANELS SUBJECTED TO OBLIQUE IMPACT OF SOFT MISSILE
}

\author{
Akemi Nishida ${ }^{1}$, Yoshimi Ohta ${ }^{2}$, Haruji Tsubota ${ }^{2}$, and Yinsheng Li $^{1}$ \\ ${ }^{1}$ Principal Researcher, Japan Atomic Energy Agency, Japan \\ ${ }^{2}$ Researcher, Japan Atomic Energy Agency, Japan
}

\begin{abstract}
Many empirical formulas have been proposed for evaluating local damage to reinforced concrete structures caused by impacts of rigid missiles. Most of these formulas have been derived based on tests involving impact perpendicular to target structures. Thus far, few tests with oblique impact onto target structures have been carried out. In this study, we aim to propose a new formula for evaluating the local damage caused by oblique impact based on previous experimental and simulation results.

In this study, we perform simulation analyses for evaluating the local damage to reinforced concrete panels subjected to oblique impacts by soft missiles under various impact velocities by using a simulation method that was validated using the results of previous impact experiments. Based on the results of these simulation analyses, quantitative evaluation of the reduction in local damage due to the difference in impact angle and impact velocity is investigated.
\end{abstract}

\section{INTRODUCTION}

Many empirical formulas have been proposed for evaluating local damage to reinforced concrete structures due to rigid missile impact (Kennedy, 1957; Li et al., 2005). Most of these formulas have been derived based on tests in which the impact is perpendicular to target structures, and few tests involving impacts oblique to target structures have been carried out, especially for soft missiles.

The goal of this work is to propose a new formula for evaluating local damage to reinforced concrete structures, such as penetration depth, scabbing limit thickness, perforation limit thickness, scabbing limit velocity, and perforation limit velocity, caused by oblique impact of soft missiles. However, given the lack of adequate extant experimental data, we must obtain the data necessary for proposing the evaluation formula by means of numerical analyses.

In this paper, we present an analytical study for evaluating local damage to reinforced concrete panels, due to oblique impact of soft missiles under various impact velocity conditions. The simulation method used herein was validated by using the results of previous impact experiments. Based on the analytical results, the influences of impact response characteristics due to differences in impact angle and impact velocity are investigated.

\section{ANALYTICAL METHOD}

For the numerical analyses, the finite element code LS-DYNA R7.1.2, along with Lagrangian finite elements and explicit time integration, was used. As presented and discussed in our previous paper (Nishida et al., 2017), the validity and applicability of this analytical method for evaluating local damage to reinforced concrete panels due to normal impact by soft missiles were verified through analyses of past experimental results (Sugano, 1993). 


\section{FINITE ELEMENT MODELING}

\section{Reinforced Concrete Panel}

The target reinforced concrete panel used in the simulation analyses is shown in Figure 1. As shown in this figure, the target panel is a $1.5 \mathrm{~m}$ square reinforced concrete panel. The thickness of the central region of the panel is set to $80 \mathrm{~mm}$ to allow for the missile to perforate it. To prevent overall bending failure of the panel, 200-mm-thick edge rib beams are attached to the peripheral regions of the panel, and additional reinforcing steel bars are installed in these rib beams.

The steel reinforcement includes deformed re-bars having a diameter of $6.0 \mathrm{~mm}$ and placed at intervals of $100 \mathrm{~mm} \mathrm{c} / \mathrm{c}$ along the two orthogonal directions on both faces. The concrete cover is $10 \mathrm{~mm}$ on both surfaces. The reinforcement ratio is $0.4 \%$ along each direction on each face.

This reinforced concrete panel is fixed at its four corners; anchor plates are attached at four fixed points each on both faces of the target panel, and they are connected by steel pipes of diameter $30 \mathrm{~mm}$.

For FE modeling, the concrete is modeled using solid elements and the steel reinforcing bars are modeled using beam elements. The anchor plates and the steel pipes attached at the four corners are modeled using shell and beam elements, respectively.

Figures 2 and 3 show the FE modeling of the target reinforced concrete panel. The size of the concrete elements is approximately $10 \mathrm{~mm} \times 10 \mathrm{~mm} \times 10 \mathrm{~mm}$. A finer element mesh is used to model the central part of the target panel. It includes eight layers along the thickness of the panel. A coarse mesh is used to model the peripheral regions of the panel.

The nodal point connecting the solid elements of the concrete and the beam elements of the reinforcing bars is set up as the same point. Therefore, in this analysis, we assume a perfect bond between the concrete and the steel reinforcing bars.

\section{Missile}

The missile employed in this paper is the same soft missile as in our previous paper (Nishida et al., 2017). This missile is a simplified 1/7.5-scale model of the GE-J79 turbo engine installed in F-4 Phantom fighters (Sugano et al., 1993).

The configuration and the size of the soft missiles employed in this simulation analysis are shown in Figure 4. As shown in this figure, the soft missile is a cylindrical shell comprising three frames, namely, front frame, intermediate frame, and rear frame, and two thin cylindrical shells, namely, front and rear shells. The thicknesses of the front, intermediate, and rear frames are $10 \mathrm{~mm}, 12 \mathrm{~mm}$, and $15 \mathrm{~mm}$, respectively. The thicknesses of the front and the rear parts of the cylindrical shell are $1.0 \mathrm{~mm}$ and 2.7 $\mathrm{mm}$, respectively. The diameter of this missile is $101 \mathrm{~mm}$, total length is $317 \mathrm{~mm}$, and weight is $3.6 \mathrm{kgf}$. The frames are modeled using solid elements, and the thin cylindrical parts are modeled using shell elements.

\section{MATERIAL MODEL}

\section{Reinforced Concrete Panel}

The material properties of the concrete used for the reinforced concrete panel are listed in Table 1 . The material model of the concrete employed for the simulation analyses is mainly the "MAT_084 
Division III

(*MAT_WINFRITH_COCRETE)" model installed in LS-DYNA. Because the strain rate effect of concrete is calculated automatically in LS-DYNA, the dynamic increase factor is not multiplied by the compressive strength and the tensile strength of the concrete.

Table 2 lists the material properties of the D6 steel rebar used in the simulation analyses. The Poisson ratio of the steel rebar is assumed as 0.3 . The true-stress-true-strain relationship of the steel rebar material is determined by assuming an exponential function that passes the yield stress point and the maximum strength point. The strain rate effect of the steel rebar is considered by applying the WES (The Japan Welding Engineering Society) Formula, defined in WES-2808 (JWES, 2003).

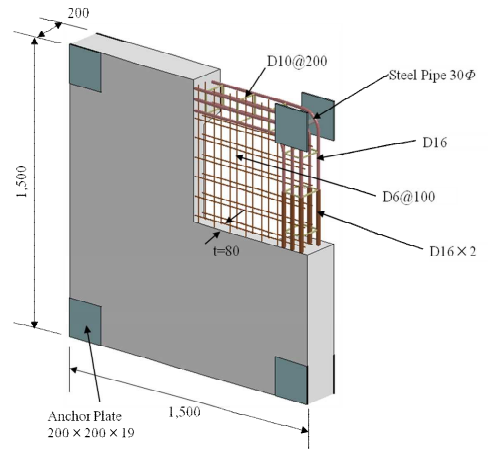

Fig. 1 Target reinforced concrete panel

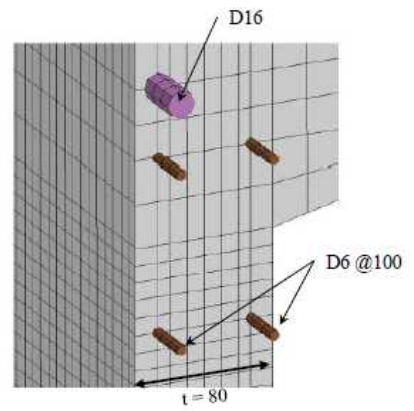

Fig. 3 Detailed FE model of target panel

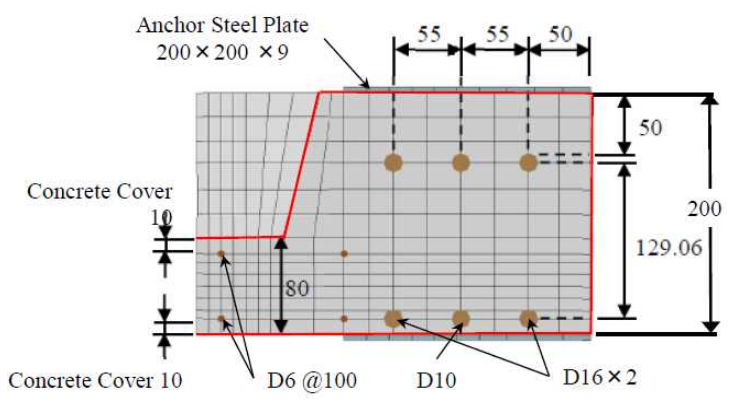

Fig. 2 FE model of target panel (unit: $\mathrm{mm}$ )

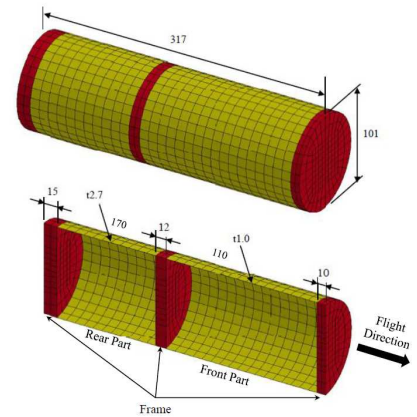

Fig.4 FE model of missile (unit: mm)

Table 1 Material properties of concrete

\begin{tabular}{|c|c|c|c|c|c|}
\hline $\begin{array}{c}\text { Compressive Strength } \\
(\mathrm{MPa})\end{array}$ & $\begin{array}{c}\text { Tensile Strength } \\
(\mathrm{MPa})\end{array}$ & $\begin{array}{c}\text { Density } \times 10^{-9} \\
\left(\mathrm{t} / \mathrm{mm}^{3}\right)\end{array}$ & $\begin{array}{c}\text { Young's Modulus } \\
(\mathrm{MPa})\end{array}$ & $\begin{array}{c}\text { Poisson } \\
\text { Ratio }\end{array}$ & $\begin{array}{c}\text { Aggregate Size } \\
(\mathrm{mm})\end{array}$ \\
\hline 25.497 & 2.354 & 2.345 & 23,131 & 0.2 & 10 \\
\hline
\end{tabular}

Table 2 Material properties of D6 steel rebar

\begin{tabular}{|c|c|c|c|c|c|}
\hline $\begin{array}{c}\text { Density } \times 10^{-9} \\
\left(\mathrm{t} / \mathrm{mm}^{3}\right)\end{array}$ & $\begin{array}{c}\text { Young's Modulus } \\
(\mathrm{MPa})\end{array}$ & $\begin{array}{c}\text { Yield Strength } \\
(\mathrm{MPa})\end{array}$ & $\begin{array}{c}\text { Nominal Tensile } \\
\text { Strength }(\mathrm{MPa})\end{array}$ & $\begin{array}{c}\text { True Tensile } \\
\text { Strength }(\mathrm{MPa})\end{array}$ & $\begin{array}{c}\text { True Fracture } \\
\text { Strain }\end{array}$ \\
\hline 7.86 & 205,000 & 447.2 & 585.5 & 985.0 & 0.200 \\
\hline
\end{tabular}

Table 3 Material properties of missile (S45C Steel)

\begin{tabular}{|c|c|c|c|c|c|}
\hline $\begin{array}{c}\text { Density } \times 10^{-9} \\
\left.\mathrm{t} / \mathrm{mm}^{3}\right)\end{array}$ & $\begin{array}{c}\text { Young's Modulus } \\
(\mathrm{MPa})\end{array}$ & $\begin{array}{c}\text { Yield Strength } \\
(\mathrm{MPa})\end{array}$ & $\begin{array}{c}\text { Nominal Tensile } \\
\text { Strength }(\mathrm{MPa})\end{array}$ & $\begin{array}{c}\text { True Tensile } \\
\text { Strength }(\mathrm{MPa})\end{array}$ & $\begin{array}{c}\text { True Fracture } \\
\text { Strain }\end{array}$ \\
\hline 7.136 & 214,000 & 411.9 & 705.1 & 846.1 & 0.191 \\
\hline
\end{tabular}

Table 4 Contact conditions and friction coefficients

\begin{tabular}{|l|l|c|}
\hline Object & Contract Condition & Friction Coefficient \\
\hline Missile-Concrete & Eroding contact & 0.30 \\
\hline Missile-Steel Rebar & Nodes to surface contact & 0.20 \\
\hline Self-contact of missile & Single-surface contact & 0.20 \\
\hline
\end{tabular}


Missile

The material used in the missile is S45C steel, and its properties are listed in Table 3. In the same way as the steel rebar, the relationship between true-stress and true-strain for $\mathrm{S} 45 \mathrm{C}$ steel is determined by assuming an exponential function that passes the yield stress point and the maximum strength point.

\section{ANALYSIS CONDITIONS}

\section{Contact Condition}

The contact conditions and the friction coefficients used in the simulation analyses are summarized in Table 4. For evaluating contact between the missile and the eroded ruptured concrete, eroding contact is defined for the missile-concrete contract. Given that the contact condition between the missile and the steel rebar is contact between the shell element and the beam element, the nodes to surface contact are used to represent missile-steel rebar contract. For missile self-contact, single-surface contact is defined.

\section{Boundary Condition}

For FE modeling, the fixed boundary conditions are set at the midpoint of the four steel pipes arranged between the anchor plates at the four corners of the target panel.

\section{Analysis Case}

A total of 12 cases of impact were analyzed by changing the impact angle to 0 (normal impact), 15, 30, and $45^{\circ}$, and impact velocity to 103,150 , and $215 \mathrm{~m} / \mathrm{s}$. Figure 5 shows the definition of impact angle.

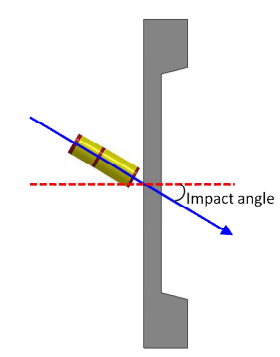

Fig. 5 Definition of impact angle
Table 5 Structural damage

\begin{tabular}{|c|c|c|c|}
\hline Angle & $103 \mathrm{~m} / \mathrm{s}$ & $150 \mathrm{~m} / \mathrm{s}$ & $215 \mathrm{~m} / \mathrm{s}$ \\
\hline $0^{\circ}$ & No obvious damage & Perforation & Perforation \\
\hline $15^{\circ}$ & No obvious damage & $\begin{array}{c}\text { Penetration } \\
\text { limit } \cdot \text { Boring }\end{array}$ & Perforation \\
\hline $30^{\circ}$ & $\begin{array}{c}\text { Damage on the } \\
\text { impact surface }\end{array}$ & $\begin{array}{c}\text { Penetration } \\
\text { Scabbing }\end{array}$ & Perforation \\
\hline $45^{\circ}$ & $\begin{array}{c}\text { Damage on the } \\
\text { impact surface }\end{array}$ & $\begin{array}{c}\text { Damage on the } \\
\text { impact surface }\end{array}$ & Perforation \\
\hline
\end{tabular}

\section{ANALYTICAL RESULTS AND CONSIDERATIONS}

\section{Impact Behavior}

The analysis pertaining to the damage mode of the target panel in all 12 cases are listed in Table 5. For the impact velocity of $215 \mathrm{~m} / \mathrm{s}$, all damage modes of the target panel are perforation.

In case of the impact velocity $215 \mathrm{~m} / \mathrm{s}$ perforation behaviors of the missile for the normal and oblique impacts with an impact angle of $45^{\circ}$ are shown in Figure 6 (a) and (b), respectively. In case of the normal impact, the missile collides with the target reinforced concrete panel perpendicularly and then penetrates and perforates along a straight line while maintaining its original posture. By contrast, in case of the oblique impact with the impact angle of $45^{\circ}$, the missile is subjected to rotational motion during perforation. Finally, the missile rotates about $180^{\circ}$ just after the end of perforation, and it moves with rotational motion after perforation.

Moreover, under the normal impact, the rigid front frame of the missile collides with the target panel in the form of a flat-nosed missile. However, in case of the oblique impact, the edge of the rigid front frame collides with the target 
panel at first. As a result, the front shell part of the missile is deformed, and it penetrates the target panel in the form of a sharp-nosed missile. This impact is expected to damage the target panel more easily (with lower energy) than the normal impact.

In case of the impact velocity of $150 \mathrm{~m} / \mathrm{s}$, as given in Table 5, the decrease in panel damage due to the difference in impact angle can be recognized clearly. For the impact angle of $0^{\circ}$, the missile perforates the panel, but when the impact angle is $15^{\circ}$, the missile penetrates the panel and is stuck in it. For the impact angle of $30^{\circ}$, scabbing is observed on the back surface of the panel. For the impact angle of $45^{\circ}$, as shown in Figure 6 (d), the front frame of missile hits the target first; thereafter, the missile slips across the target, and then, the rear part of the missile hits the target secondary. Therefore, the damage is further reduced and limited to penetration on the impact surface.

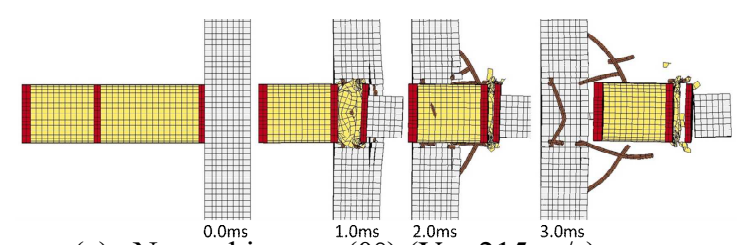

(a) Normal impact $\left.\left(0^{\circ}\right) \stackrel{2.0 \mathrm{~ms}}{(\mathrm{~V} \mathrm{~ms}}=215 \mathrm{~m} / \mathrm{m} / \mathrm{s}\right)$

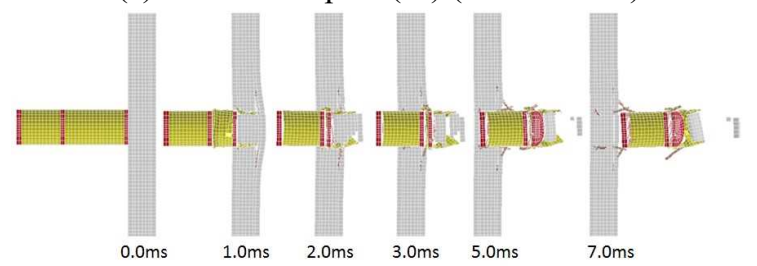

(c) Normal impact $\left(0^{\circ}\right)(\mathrm{V}=150 \mathrm{~m} / \mathrm{s})$

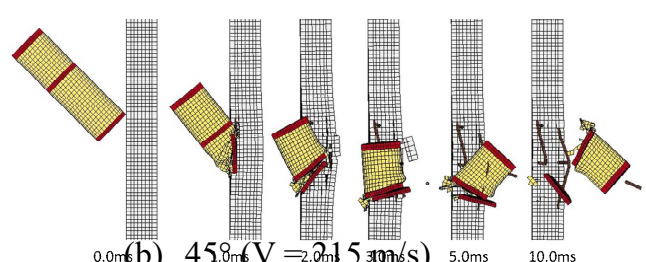

$0.0 \mathrm{~m}(\mathrm{~b}) \quad 45.8 \mathrm{~m}(\mathrm{~V}=2.2 \mathrm{~m} 15$ anm $6 \mathrm{~s}) \quad \begin{array}{ll}5.0 \mathrm{~ms} & 10.0 \mathrm{~ms}\end{array}$

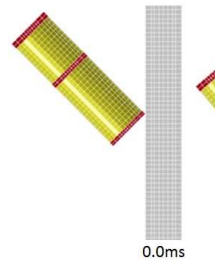

(d) $45^{\circ}(\mathrm{V}=150 \mathrm{~m} / \mathrm{s})$

Fig. 6 Impact behavior of missile

\section{Damage Mode of RC Panel}

Figure 7 shows the damage modes of the RC panel. In the case of the impact velocity of $215 \mathrm{~m} / \mathrm{s}$, a square perforation hole of approximately $120 \mathrm{~mm}$ side length, slightly larger than the diameter $(101 \mathrm{~mm})$ of the missile, is formed under the normal impact. For the oblique impacts, by contrast, a rectangular perforation hole is generated gradually as the impact angle increases. For the oblique impact with the impact angle of $45^{\circ}$, the long side of the perforation measures $200 \mathrm{~mm}$, which is approximately twice the spacing of the reinforcing rebar. This indicates that the size of the perforation size is affected by the rebar spacing. Furthermore, the volume of the perforation hole generated by the oblique impact is larger than that of the perforation generated by the normal impact. By contrast, the scabbed area on the back face of the target panel is the widest in case of the normal impact.

Figure 8 shows the relationship between the surface crater depth of the RC panel due to missile impact and impact velocity. From this figure, the depth of the surface crater tends to decrease with increasing impact angle. Moreover, Figure 8(b) shows the typical damage modes of the RC panel for the impact angle $30^{\circ}$ in the case of the impact velocities of $150 \mathrm{~m} / \mathrm{s}$ and $103 \mathrm{~m} / \mathrm{s}$. Especially, in case of the impact velocity of $103 \mathrm{~m} / \mathrm{s}$, no obvious damage such as penetration is observed on the impact surface of the RC panel for the impact angles of 0 and $15^{\circ}$.

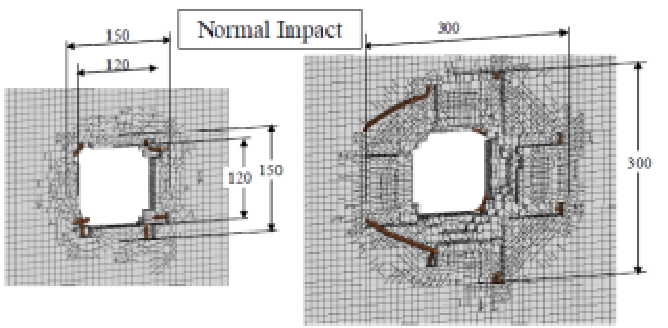

(b)

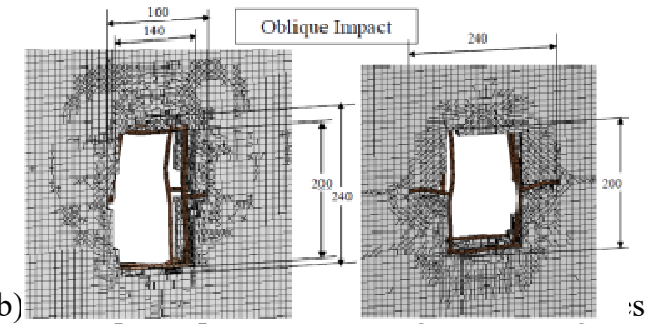

Fig. 7 Damage modes of the RC panel $(\mathrm{V}=215 \mathrm{~m} / \mathrm{s})$ 


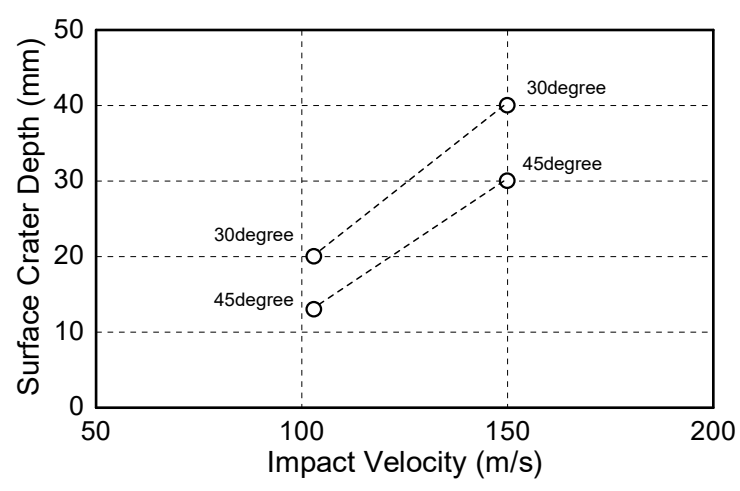

(a) Impact velocity vs surface crater depth

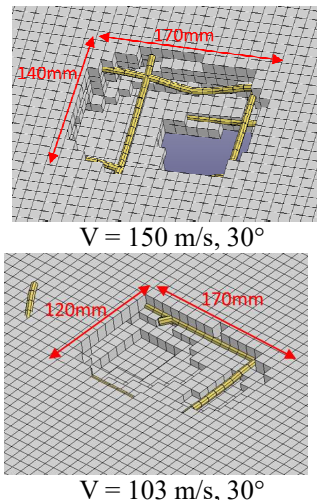

(b) typical damage

Fig.8 Surface crater depth

\section{Damage Mode of Missile}

The analytical results pertaining to the damage modes of the missile with the impact velocity of $215 \mathrm{~m} / \mathrm{s}$ after perforation are shown in Figure 9. For the normal and the oblique impacts, the front part of the cylindrical shell measuring $1.0 \mathrm{~mm}$ in thickness is ruptured and separated from the remainder of the missile. By contrast, the rear part of the cylindrical shell measuring $2.7 \mathrm{~mm}$ in thickness retains its original configuration in all cases. For the normal impact, especially, no buckling mode is observed in the rear part of the cylindrical shell. As shown in Figure 9, however, for the oblique impacts, especially for the impact angle of $45^{\circ}$, a non-axisymmetric buckling mode is extended to the rear part of the cylindrical shell. The final length of the remaining part of the missile after perforation for the normal impact is larger than that for the oblique impacts.

From the results, the larger the impact angle, the larger are the damage and the destruction area of the missile. Therefore, we suggest that the energy consumed by the damage and destruction caused by the missile increases with increasing impact angle.

Figure 10 shows the damage state of the missiles for the impact velocity of $103 \mathrm{~m} / \mathrm{s}$. As shown in the figure, even in the case of the low impact velocity, the thin-walled shell in the front part of the missile shows buckling and the thick-walled shell in the rear part of the missile does not show buckling. The buckled region in the front thin-walled shell part is the largest when the impact angle is $0^{\circ}$ because of the axisymmetric buckling mode, which extends over the entire thin-walled shell of the rear part. In addition, the buckling indicates the non-axisymmetric mode, and the buckled region tends to decrease in size with increasing impact angle. However, in case of the impact velocity of $103 \mathrm{~m} / \mathrm{s}$ and the impact angle of $45^{\circ}$, the missile rebounds after first colliding with the RC panel, and then the rear part of the missile collides with the RC panel secondary, so the rear thick-walled shell part is damaged.

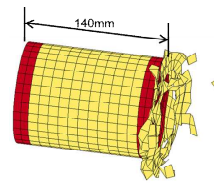

(a) $0^{\circ}$
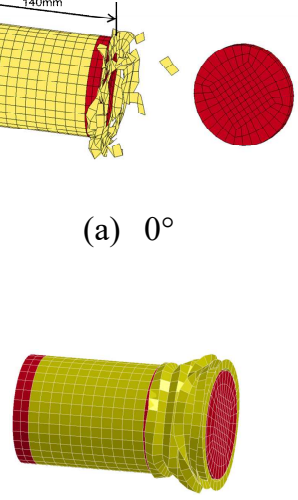

(a) $0^{\circ}$

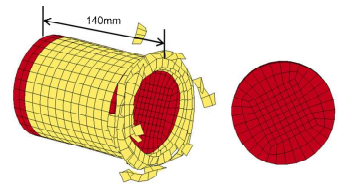

(b) $15^{\circ}$

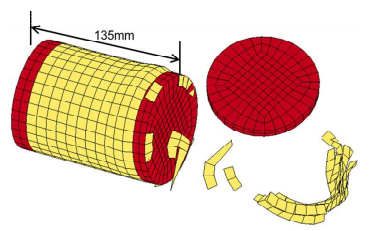

(c) $30^{\circ}$

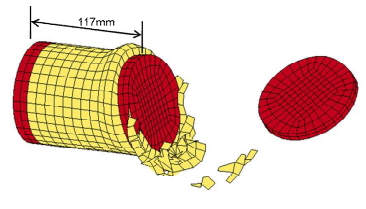

(d) $45^{\circ}$

Fig. 9 Damage to missile $(\mathrm{V}=215 \mathrm{~m} / \mathrm{s})$

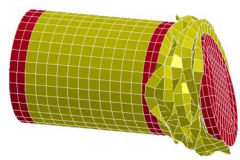

(b) $15^{\circ}$

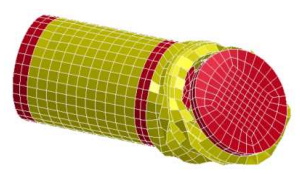

(c) $30^{\circ}$

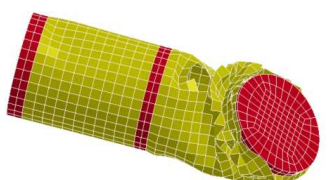

(d) $45^{\circ}$

Fig. 10 Damage to missile $(\mathrm{V}=103 \mathrm{~m} / \mathrm{s})$ 


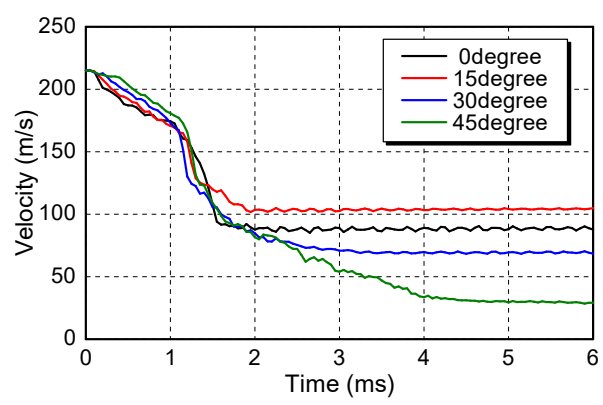

(a) $\mathrm{V}=215 \mathrm{~m} / \mathrm{s}$

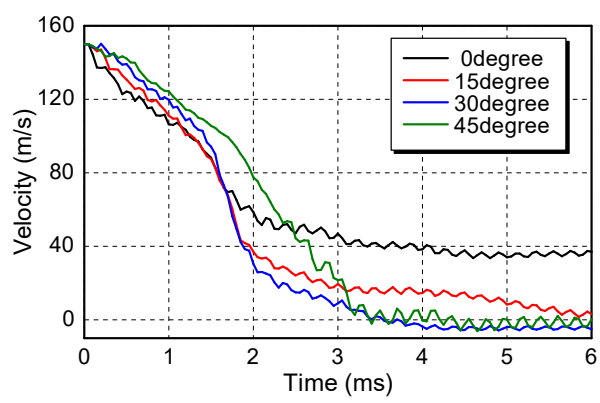

(b) $\mathrm{V}=150 \mathrm{~m} / \mathrm{s}$

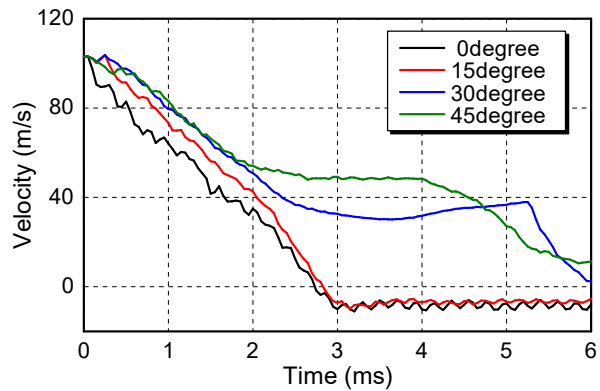

(c) $\mathrm{V}=103 \mathrm{~m} / \mathrm{s}$

Fig. 11 Change in missile velocity

\section{Change in Missile Velocity}

Changes in the velocity of the missile at the center of the rear frame are shown in Figure 11. In case of the impact velocity of $215 \mathrm{~m} / \mathrm{s}$, as shown in Figure 11 (a), from the start of collision to $1.0 \mathrm{~ms}$, the reduction in missile velocity is larger in case of the normal impact than that in case of the oblique impacts. Thereafter, the velocity decreases according to almost the same tendency for the normal and the oblique impacts. In case of the normal impact, it takes $1.5 \mathrm{~ms}$ for the missile to pass the target panel, and the residual velocity of the missile after perforation is $90.0 \mathrm{~m} / \mathrm{s}$. For the oblique impacts, however, it takes more time to pass the target panel because the equivalent panel thickness, measured along the flight direction, increases. In the analytical results, the residual velocities of the missile after perforation by the oblique impacts are about 105,70 , and $10.0 \mathrm{~m} / \mathrm{s}$ for the impact angles of 15,30, and $45^{\circ}$, respectively. That is, the larger the impact angle, the lower is the residual velocity after perforation. By contrast, the residual velocity after perforation in case of the oblique impact with the impact angle of $15^{\circ}$ is larger than that in case of the normal impact. This is discussed under energy consideration in Section 4.

In the case of the impact velocity of $150 \mathrm{~m} / \mathrm{s}$, as shown in Figure 11 (b), the missile passes through the RC panel at about $3.0 \mathrm{~ms}$ after collision in case of the normal impact, and the residual velocity after perforation is about $35 \mathrm{~m} / \mathrm{s}$. Moreover, in case of the impact angles of 15 and $30^{\circ}$, the missile decelerates in two steps: until $2.0 \mathrm{~ms}$ after the collision, the deceleration trend is the same as in case of the normal impact, and after $2.0 \mathrm{~ms}$, the deceleration is more gradual. Finally, the missile velocity gradually decreases to almost zero at about $3.5 \mathrm{~ms}$. By contrast, in case of the impact angle of $45^{\circ}$, almost constant deceleration can be seen from the start of collision to about $3.5 \mathrm{~ms}$.

In case of the impact velocity of $103 \mathrm{~m} / \mathrm{s}$, as shown in Figure 11 (c), the impact velocity decreases almost linearly from the start of impact to about $3.0 \mathrm{~ms}$ for the impact angles of 0 and $15^{\circ}$, and the missile rebounds off the target panel. Then, the missile has negative velocity. Judging from this figure, the velocity of the missile after rebounding is about $10.0 \mathrm{~m} / \mathrm{s}$.

By contrast, as shown in Figure 11 (c), in case of the impact angles of 30 and $45^{\circ}$, the front frame of the missile hits the target first, and then, the missile slips across the target, and the rear part of the missile hits the target secondary. Therefore, the deceleration curve becomes complicated. Especially for the impact angle of $30^{\circ}$ and $45^{\circ}$, the missile decelerates monotonously up to $3.0 \mathrm{~ms}$ after collision, and then, it missile moves at a constant velocity without deceleration from $3.0 \mathrm{~ms}$ to $5.0 \mathrm{~ms}$ before decelerating suddenly thereafter. The missile moves while sliding on the 
surface of the RC panel from $3.0 \mathrm{~ms}$ to $5.0 \mathrm{~ms}$, and the rear frame of the missile collides with the surface of the RC panel again at $5.0 \mathrm{~ms}$, which causes the aforementioned rapid deceleration.

\section{Time History of Energy Transfer Process}

Figure 12 shows the time history of the energy transfer process in cases of the normal impact and the oblique impacts for the impact velocity of $215 \mathrm{~m} / \mathrm{s}$. The definitions of the symbols in these figures are as follows:

KE (Missile): Kinematic energy consumed by missile

KE (Target): Kinematic energy consumed by target panel

IE (Missile): Internal energy consumed by rupture and deformation of missile

IE (Target): Internal energy consumed by rupture and deformation of target panel

Sliding energy is the energy consumed at the contact surface between missile and target panel.

Figure 12(a) shows the total internal energy (TIE) consumed by the rupture and deformation of the target panel, and the total kinematic energy (TKE) consumed by the target panel. As shown in the figure, the energy consumed for rupture of the target panel is the largest in the case of the normal impact. On the contrary, in case of the oblique impacts, the TIE of the target panel increases as the impact angle increases. This tendency is consistent with the evaluation result of the previous section that the equivalent thickness of the target panel and the volume of the perforation increase as the impact angle increases. Moreover, the TIE of the target panel in case of the normal impact is larger than that in case of the oblique impacts because, as described in Section 2, the scabbing area of the back face of the target panel in case of the normal impact is considerably larger than that in case of the oblique impacts, and the energy consumed for the rupture of the target panel increases. However, the volume of the perforation in case of the oblique impacts is greater than that in case of the normal impact.

Figure 12(a) also shows the TKE consumed by target panel, which is mainly consumed by perforation and scabbing of the target panel. The characteristic trend in this figure is that in case of the normal impact, TKE increases markedly at about $1.6 \mathrm{~ms}$ after impact, because, as described above, the scabbing phenomenon of the target panel in case of the normal impact starts at this time, and the scabbing region is larger than that in case of the oblique impacts. Furthermore, the scabbing velocity of the scabbed debris in case of the normal impact is larger than that in case of the oblique impacts.

Figure 12(b) shows the TIE consumed by rupture of the missile and the TKE consumed by missile. As shown in this figure, the larger the impact angle, the larger is the damage and destruction area of the missile. Thus, the TIE of the missile tends to increase with increasing impact angle.

Figure 12(b) also shows the TKE consumed by missile. Regarding TKE of the missile, reduction of the missile TKE is more prominent at $1.1 \mathrm{~ms}$ after impact in case of the oblique impact with the impact angle of $45^{\circ}$. It seems that this is because the missile undergoes rotational motion when penetrating the target panel, and as a result, the rear frame of the missile re-collides with the perforation in the target panel and the missile velocity decreases. This trend is consistent with the result of the missile's velocity change shown in Figure 11.

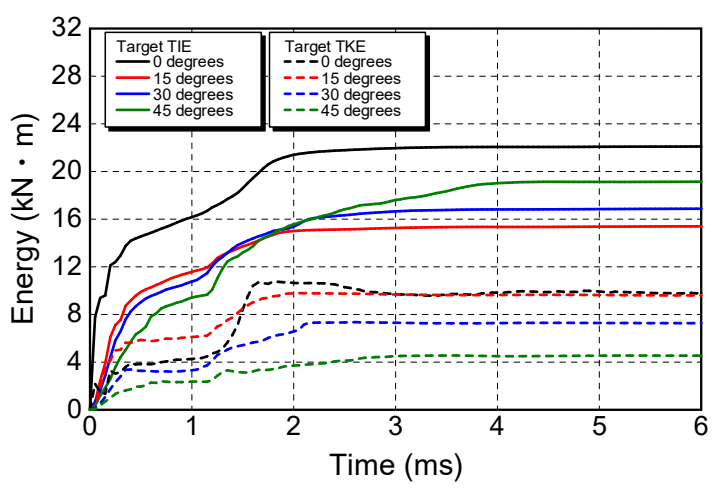

(a) Target panel (TIE and TKE)

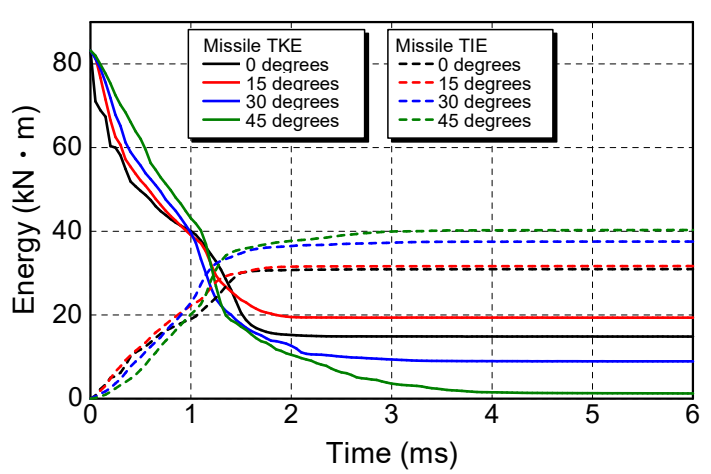

(b) Missile (TIE and TKE)

Fig. 12 Time history of energy transfer $(\mathrm{V}=215 \mathrm{~m} / \mathrm{s})$ 
Time history of energy transfer for the impact velocity of $103 \mathrm{~m} / \mathrm{s}$ is shown in Figure 13 . In case of the impact velocity of $103 \mathrm{~m} / \mathrm{s}$, the energy consumed by destruction and deformation of the target RC panel (TIE of target panel) is the maximum in case of the normal impact, and damage to the panel ends within about $1.5 \mathrm{~ms}$ after collision. In cases of the impact angles of 30 and $45^{\circ}$, an increase in energy is observed at $\mathrm{t}=0.5 \mathrm{~ms}$ and $5.5 \mathrm{~ms}$. As mentioned above, the increase in energy at $0.5 \mathrm{~ms}$ is due to the first collision of the missile, and the increase in energy at $5.5 \mathrm{~ms}$ is due to the second collision after the missile rebounds.

The energy consumed by the missile's destruction and deformation (TIE of missile) is the maximum for the impact angle of $15^{\circ}$ and the minimum for the impact angle of $45^{\circ}$. This trend is consistent with the result of missile damage shown in Figure 9. Moreover, the time history response of missile TKE shows that the kinetic energy becomes zero at $2.5 \mathrm{~ms}$ after collision for the impact angles of 0 and $15^{\circ}$. It can be confirmed that penetration by the missile ends at this time, and then the missile rebounds. By contrast, continuation of kinetic energy due to slip motion is observed even after $5.0 \mathrm{~ms}$ since collision for the impact angles of 30 and $45^{\circ}$.

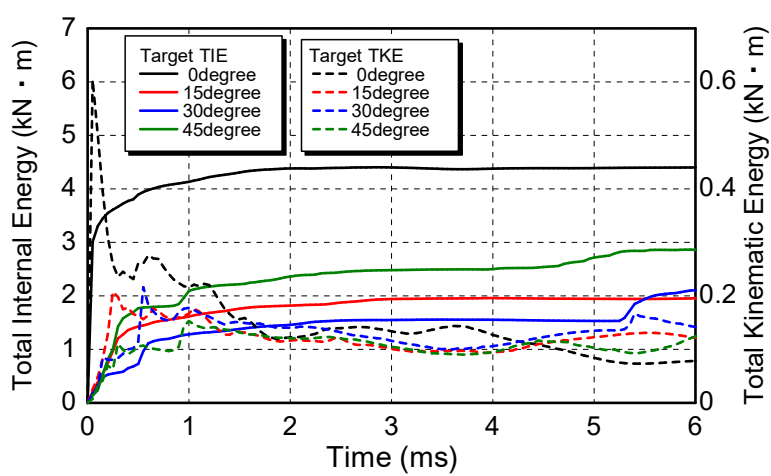

(a) Target panel (TIE vs. TKE)

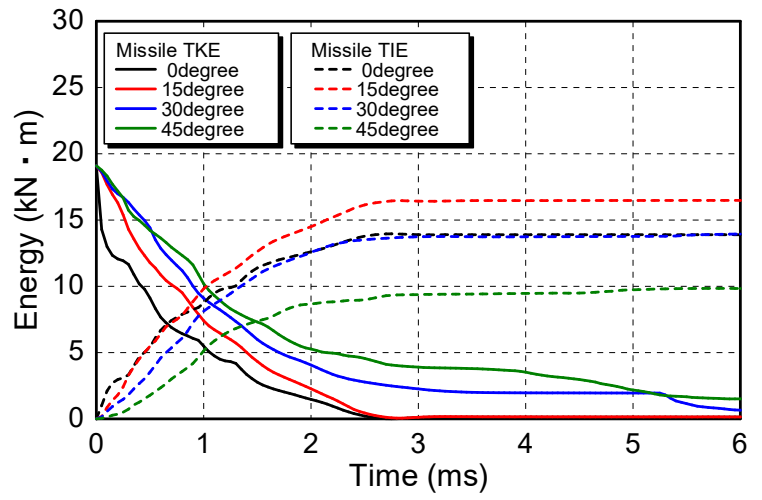

(b) Missile (TIE vs. TKE)

Fig. 13 Time history of energy transfer $(\mathrm{V}=103 \mathrm{~m} / \mathrm{s})$

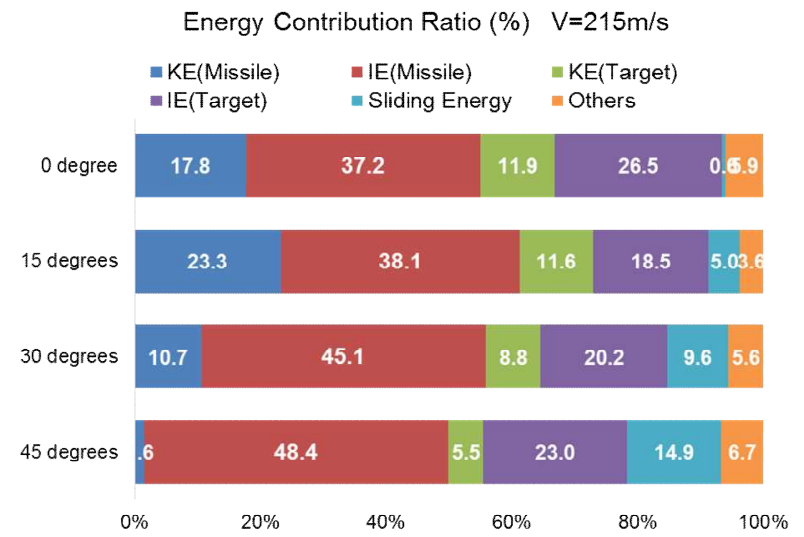

(a) $\mathrm{V}=215 \mathrm{~m} / \mathrm{s}$

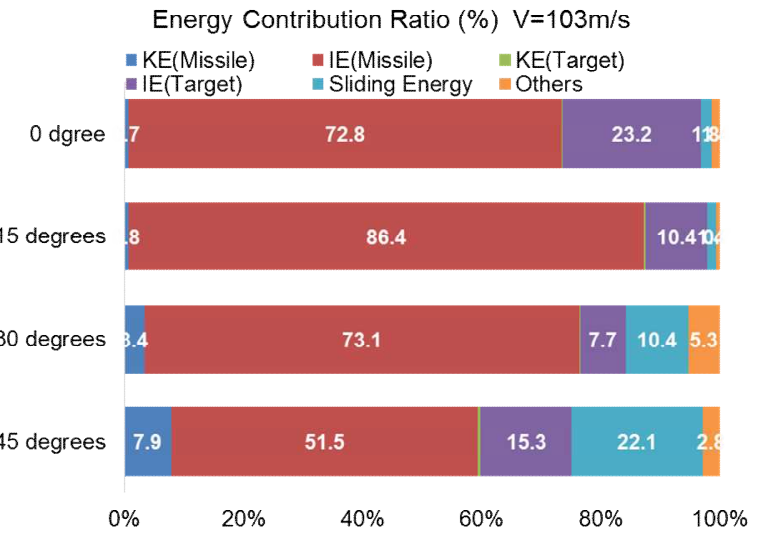

(b) $\mathrm{V}=103 \mathrm{~m} / \mathrm{s}$

Fig. 14 Energy contribution ratio

The energy contribution ratios at the end of the collision are shown in Figure 14. Figure 14 (a) shows the energy contribution ratio after the missile perforates at $\mathrm{t}=5.0 \mathrm{~ms}$ for the impact velocity of $215 \mathrm{~m} / \mathrm{s}$. As shown in this figure, the initial kinematic energy of the missile is transformed to the internal energy consumed by the rupture and plastic deformation of the missile and the target panel, as well as other forms of energy such as sliding energy.

Given that the residual velocity of the missile after perforation in case of the normal impact is larger than that in case of the oblique impacts, the final kinematic energy of the missile after perforation, KE (missile), is larger in case of 
the normal impact than that in case of the oblique impacts. The internal energy consumed by the rupture and plastic deformation of the missile, IE (missile), in case of the oblique impacts is larger than that in case of the normal impact because missile damage and deformation in case of the oblique impacts is larger than that in case of the normal impact, as discussed in Section 6.2. The internal energy consumed by the rupture and plastic deformation of the target panel, IE (Target), is almost the same in cases of the normal and the oblique impacts.

The largest energy consumption component from the viewpoint of the energy contribution ratio is the internal energy consumed for missile rupture and plastic deformation, accounting for approximately $40 \%$ of the initial kinetic energy of the missile before impact. Because the destructive/deformation energy of a rigid missile is zero, it can be understood from this fact that the damage to the target by the soft missile is reduced as compared that by a rigid missile.

Figure 14 (b) shows the energy contribution ratio at the end of the collision event (at $10.0 \mathrm{~ms}$ ) for the impact velocity of $103 \mathrm{~m} / \mathrm{s}$. As shown in this figure, $50-80 \%$ of the initial kinetic energy of the missile is consumed in the destruction/deformation of the missile, IE (Missile). IE (Missile) is the maximum for the impact angle of $15^{\circ}$, and it decreases as the impact angle increases.

By contrast, the energy consumed by the destruction and deformation of the target RC panel, IE (Target), is the maximum in case of the normal impact, and it tends to decrease as the impact angle increases. However, for the impact angle of $45^{\circ}$, IE (Target) is larger than that in cases of the impact angles of 15 and $30^{\circ}$ because the missile rebounds while sliding and collides with the RC panel again after the first collision, as described before. The sliding energy consumed for contact and friction between the missile and the RC panel tends to increase as the impact angle increases, as in case of the impact velocity of $215 \mathrm{~m} / \mathrm{s}$. Especially, for the impact angle of $45^{\circ}$, the missile collides with the RC panel twice, as described above, so the sliding energy is larger in this case than in cases of the other impact velocities.

\section{CONCLUSION}

In this study, the perforation behavior of a reinforced concrete panel subjected to oblique impact by soft missiles under various impact velocities was investigated analytically. As a result, various response characteristics such as impact behavior, damage to reinforced concrete panels, rupture and deformation of soft missile, reduction tendency and residual of the missile velocity, and energy transfer process were clarified.

Hereon, we will continue to perform simulation analyses by using various types of missiles such as rigid missiles and sharp-nosed missiles. Finally, we will attempt to propose a new formula for evaluating the local damage to a RC panel due to oblique impact by soft missiles.

\section{REFERENCES}

R. P. Kennedy, 1976, "A review of procedure for the analysis and design of concrete structures to resist missile impact effects", Nuclear Engineering and Design 37, pp.183-203

Q. M. Li, S. R. Reid, H. M. Wen, and A. R. Telford, 2005, "Local impact effects of hard missiles on concrete targets", International Journal of Impact Engineering 32, pp. 224-284

Nishida A., Ohta Y., and Tsubota H. and Li Y., 2017, "A Study for Evaluating Local Damage to Reinforced Concrete Panels Subjected to Oblique Impact. Part2: Simulation Analysis of the Experimental Results of Local Damage Caused by Impact of Deformable Projectiles, Proceedings of the 25th International Conference on Nuclear Engineering ICONE25, 2017, Shanghai, China

T. Sugano, H. Tsubota, Y. Kasai, N. Koshika, H. Ohnuma, W. A. von Riesemann, D. C. Bickel and M. B. Parks, 1993, "Local damage to reinforced concrete structures caused by impact of engine missiles, Part1. Test program, method and results", Nuclear Engineering and Design 140, pp 387-405

WES 2808, 2003 "Method of assessing brittle fracture in steel weldments subjected to large cyclic and dynamic strain", The Japan Welding Engineering Society 